\title{
Über die bedingte Unabhängigkeit der Entwickelung des polar differenzirten Eies von der Schwerkraft.
}

\author{
Von \\ Dr. phil. et med. L. Kathariner, \\ Freiburg (Schweiz).
}

Mit 1 Figur im Text.

Eingegangen am 31. Nai 1901.

Pflüger veröffentlichte in den Jahren 1883 und $1884(1,2,3)$ Beobachtungen, aus denen sich das Vorhandensein bestimmter Beziehungen zwischen der Lage der ersten Furchungsebenen am Ei des Frosches zur Richtung der Schwerkraft ergaben. Daraus, dass der Urmund dicht unterhalb des jeweilig horizontalen Äquators liegt und durch die vertikale Medianebene halbirt wird, schloss PFLëger ferner auf ein Princip, "demzufolge die Schwerkraft einen maßgebenden Einfluss auf die Lage der Organe im Ei ausübt«. Bei genauerer Überlegung beweisen eigentlich schon die Versuche PrLC̈Gris's, dass der Verlauf der Theilung des polar differenzirten Eies durch die ihm angeborene Anordnung seines verschiedenartigen Inhaltes geregelt wird, dass seine Entwickelung ein Process der Selbstdifferenzirung ist, der allerdings in Anpassung an die Schwerkraft als an eine gegebene Bedingung verlänft und durch Störung dieser Anpassung in andere Bahnen geleitet, bezw. unterbrochen werden kann.

Für eine ursächliche Beziehung der Gravitation zur Entwickelung oder für ihre Bedentung als einer conditio sine qua non folgt dagegen aus PFL̈̈GER's Versuchen nichts, wie er denn auch die Frage, ob eine Zelle noch nach Elimination der Schwerkraft sich zu theilen vermöge, offen lässt.

Die Lösung derselben wurde von Rocx (4) in Angriff genommen. Roux ließ in ihren Hüllen bewegliche Froscheier auf einem 
Klinostaten um eine horizontale Achse rotiren und zwar mit so geringer Umdrehungsgeschwindigkeit, dass die Centrifugalwirkung keinen richtenden Einfluss ausüben konnte, andererseits aber auch der richtende Einfluss der Schwerkraft anfgehoben war. Aus dem trotzdem normalen Verlauf der Entwickelnng schloss Roux, dass die Schwerkraft für sie nicht nöthig sei.

O. Schultze wandte sich erstmalig $1894(9,10)$ gegen diese Auffassung und vertritt seitdem in einer Reihe von Veröffentlichungen, die entsprechende Entgegnungen Roux's zur Folge hatten, die Nothwendigkeit der richtenden Wirkung der Schwerkraft für die normale Entwickelung des thierischen Eies.

Auf die von Rauber (5) und Schultze in dieser Richtung verwertheten Beobachtungen an Eiern, die in abnormer Lage fixirt waren, einzugehen, erübrigt sich desshalb, weil bei den betreffenden Versuchen nicht die Ausschaltung der Schwerkraft, sondern eine abnorme Einwirkung derselben auf das Ei als Faktor in Frage kommt, durch welchen der Eiinhalt mehr oder weniger durch einander gemischt wurde, wie dies schon Bons (8) beobachtet hatte. Dass abnorme Entwickelung bezw. Entwickelungsstillstand die Folge war, ist so wenig verwunderlich, als wenn anf andere mechanische Weise, z. B. Durcheinanderriuhren des Inhalts mittels eines Glasfadens die normale Struktur des Eies gestört würde, und sich ähnliche Folgen zeigten. Nicht die Nothwendigkeit normaler Schwerkraftwirkung, sondern die Nothwendigkeit der "Normalität * der Schwerkraftwirkung kann so bewiesen werden. Aus der schädlichen Wirkung eines unrichtig dosirten Arzneimittels folgt nicht die Unentbehrlichkeit des richtig dosirten Medikaments, sondern die Nothwendigkeit seiner richtigen Dosirung.

Der seiner Zeit von Schultze (10) angezogene Vergleich: Wein ich einem Frosch ungünstige Nahrung gebe und er geht zu Grunde, muss ich den Schluss ziehen, dass die richtige Nahrung für ihn nöthig ist, stimmt desshalb nicht, weil es von vorn herein feststeht, dass Nahrung überhaupt für das Leben des Frosches unentbehrlich ist.

Wenn man dagegen aus den schädlichen Folgen abnormaler Schwerkraftwirkung auf die Nothwendigkeit normaler Schwerkraft schließen will, muss man voraussetzen, dass die Schwerkraft überhaupt für das Froschei zur Entwickelung nöthig ist, eine Voraussetzung, die ja gerade erst bewiesen werden soll. Dem Sinne nach derselbe Einwand wurde Schuctze schon von Rovx auf der Straßburger Anatomenversammlung und später wiederholt, ebenso in der 
physikalisch-medicinischen Gesellschaft zu Würburg 1894 von FICK und Boveri gemacht. Wenn Schultze später (12) "um die Kritiker zu befriedigen * bereit ist, zu seiner Behauptung von der Nothwendigkeit der normalen Schwerkraftwirkung den Zusatz anznerkennen, "so lange die Schwerkraft wirkt«, so giebt er damit in Wirklichkeit auf, was er bis dahin behauptet hatte und noch später wiederholt behauptet $(17,19)$, nämlich, dass der normale Schwerkrafteinfluss an sich für das $\mathrm{Ei}$ zu seiner Entwickelung nöthig ist.

Es lässt sich dies nur aus der ausgesprochenen Ansicht Schultze's (19) erklären, dass das Ei nie, auch nicht im Experiment dem Einfluss der Schwerkraft entzogen werden könne. Unter dieser Voraussetzung wäre zwar die Entbehrlichkeit der Schwerkraftwirkung nicht zu beweisen, aber auch ihre Nothwendigkeit wäre dadurch noch nicht bewiesen.

Unverständlich ist es mir, wie O. Hertwig (15) die Abhängigkeit der symmetrischen Entwickelnng vom richtenden Einfluss der Schwere ans Versuchen mit Froscheiern nachweisen will, die, zwischen Glasplatten gepresst, asymmetrische Embryonen lieferten.

Um den Einfluss einer abnormalen Bedingung (hier der abnorm gerichteten Schwerkraft) unzweideutig zu erkennen, gestaltet man sonst im Experiment alle anderen Bedingungen thunlichst normal. HerTwig verwerthet bei seinem Versuch einen weiteren, intensiv wirkenden abnormalen Faktor (Pressung) und ignorirt ihn in der Schlussfolgerung.

Außerdem, wenn die durch die Pressung direkt bewirkte, wohl stets mehr oder weniger asymmetrische Verlagerung der Eisubstanzen durch die Schwerkraft nicht korrigirt werden kann und Asymmetrie des Embryos zur Folge hat, so folgt daraus für die Nothwendigkeit der Schwerkraft als »ordnendes Regulativ « für das ungestört gelassene Ei gar nichts.

Hertwig (7) hat s. Z. selbst am alecithalen ${ }^{1)}$ Ei des Seeigels beobachtet, dass die Lage der Furchungsebenen von der Organisation des Eies, nicht von der Schwerkraft abhängig ist.

Bevor ich zu Versuchen ubbergehe, bei welchen die Eier des Frosches sich normal bis zu freilebenden Larven entwickelten, obschon sie jedem richtenden Einfluss der Schwere oder einer anderen

1) Da neuerdings von Boven (Über die Polarität des Seeigeleies. Verhandl. Phys. MIed. Ges. Würzburg. Y. F. Bd. XXXIV. 1901) die polare Differenzirung des seeigeleies nachgewiesen ist, so bilden diese Beobachtungen HerTwig's einen weiteren Beweis fuir die Selbstdifferenzirung des polaren Eies. 
gleichartigen Kraft entzogen waren, seien zunächst einige Überlegungen der Frage gewidmet, ob Klinostatenversuche überhaupt zur Lösung des fraglichen Problems verwerthbar sind, d. h.: kann bei denselben die richtende Wirkung der Schwerkraft aufgehoben werden, ohne
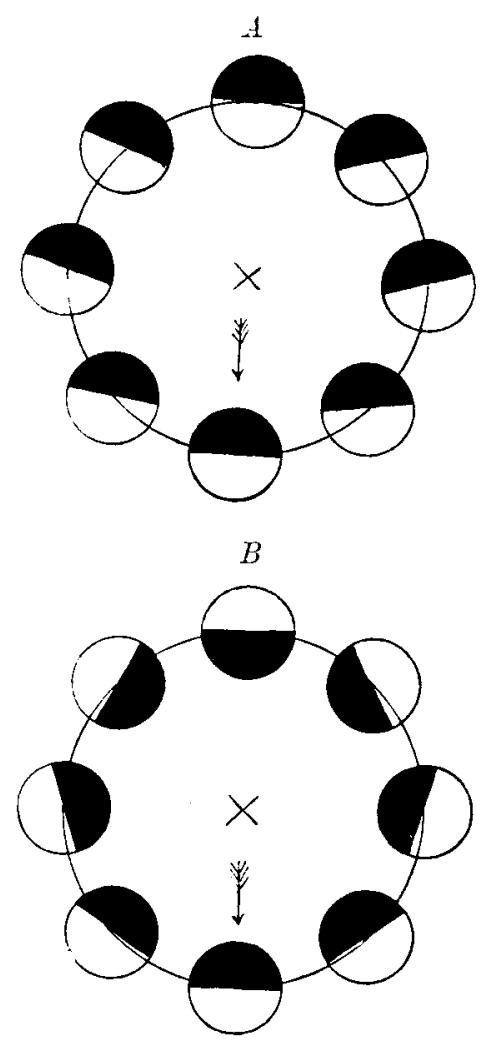

Lageu des in seinen H.üllen beweglichen Eies bei der Rotation um eine horizontale Achse, wenn die Centrifugaliraft kleiner $(-A)$ oder größer $(B)$ ist, als die Schwerkraft. Der Pfeil deutet die Richtung des Lotes an. Die weiße Hālfte ist die schwerere. Die Eihülle ist nicht gezeichnet. dass sie durch die einer anderen Kraft ersetzt wird? Ich verneine die Frage auf Grund folgender Erwägungen. Man unterscheide zunächst, ob es sich um in den Hüllen drehbare oder fixirte Eier handelt, dann weiter das Verhältnis der Centrifugalkraft zur Schwerkraft, das bekanntlich vom Radius und der Umdrehungsgeschwindigkeit äbhängt.

I. Eier in den Hiullen drehbar; Reibungswiderstand $=0$ angenommen.

1) Der Schwerkraft gegenüber komme die sehr kleine Centrifugalkraft nicht in Betracht und könne gleich Null gesetzt werden. Die Symmetrieachse des Eies fällt dann stets mit dem Loth zusammen; der Schwerpunkt liegt stets senkrecht unter dem mathematischen Nittelpnukt. Dieser Fall würde bei ganz langsamer Rotation gegeben sein.

2) Centrifugalkraft von endlicher Größe, kleiner, gleich, oder größer als die Schwerkraft (Schema $A, B$ ).

Die Eiachse stellt sich in jedem Momente der Umdrehung in die Resultante des jeweilig aus Centrifugalund Schwerkraftlinie zu konstruirenden Kräfteparallelogramms ein. Sie bildet mit dem Loth einen Winkel, dessen Größe bei jeder Umdrehung von 0 bis zu einem von der Größe der Centrifugalkraft abhängigen Maximum wächst und wieder bis 0 abnimmt. Das Maximum kann $180^{\circ}$ betragen.

3) Die Centrifugalkraft allein als wirkende Kraft anzunehmen und die Schwerkraft gleich 0 zu setzen, geht desshalb nicht an, weil 
letztere eine stets gegebene endliche Größe darstellt, nicht wie erstere von 0 an wächst.

In Wirklichkeit ist nun noch der Reibungswiderstand zu beriicksichtigen, den das Ei bei der Rotation an seiner Hïlle erfährt. Derselbe ist je nach dem Quellungszustand bezw. der Menge der Perivitellinflüssigkeit verschieden groß. Liegt seine Größe zwischen 0 und der Größe der Schwerkraft, so wird die Abweichung der Eiachse vom Loth (im Vergleich zu der ohne Reibung angenommenen) um eine der Differenz beider Kräfte entsprechende Winkelgröße wachsen. Da die Reibung jedenfalls eine gewisse Größe hat, so befindet sich anch das in den Hüllen frei bewegliche Ei während der meisten Phasen der Rotation in einer, wenn auch noch so geringen Zwangslage, da seine Symmetrieachse nicht genau mit der Richtung der jeweiligen Kraftlinie zusammenfällt. Da aber eine Abweichung von der Richtung der Gravitation bis zu $40^{\circ}$ die normale Entwickelung nicht beeinflusst, so gilt dasselbe auch für eine durch die Reibung herbeigeführte Winkelabweichung von einer anderen Kraftlinie bis zu diesem Betrag.

Bei der Rotation des in seiner Hulle drehbaren Eies tritt an die Stelle der Schwerkraft eine andere richtende Kraft, die gerade wie diese die Symmetrieachse des Eies in ihre Richtung einstellt.

Ein derartiger Versuch beweist zwar, dass ein Zusammenfallen der Eiachse mit der Erdachse zur normalen Entwickelung nicht nöthig ist; für die Entbehrlichkeit einer richtenden Kraft iiberhaupt ist er aber nicht zu verwerthen.

Von diesem Gesichtspunkt aus ist der Rovx'sche Klinostatenversuch zu beurtheilen. Die Eier entwickelten sich hier normal, nicht, weil die abnorm angreifende Schwerkraft, wie Schurrze (10) meint, »keine Zeit gewinnt", ihre Struktur zu beeinflussen, sondern weil eine abnorm angreifende Schwerkraft ïberhaupt nicht vorhanden ist. Dieselbe ist entweder normal angreifend, oder durch die Resultante aus ihr und der Centrifugalkraft ersetzt. Damit erledigt sich auch der zweite von Schultze (19) gegen Roux geltend gemachte Einwand, dass nämlich das $\mathrm{Ei}$ in kurzen Pausen in Normalstellung zurückkehre, als überflüssig. Außerdem ist aber derselbe unzutreffend. Die »normale "Stellung dauert nicht länger, als jede einzelne »abnormale". Die Summe der Dauer der letzteren aber ist natuirlich viel größer, als eine einzelne Phase, kann dieser gegenüber nie als "kurze Pause" gelten. Die "Normalstellung" wird auch nicht in 
jedem Umlauf *einmal oder häufiger" erreicht, es handelt sich vielmehr um ganz bestimmte Zahlen; zweimal tritt "Normalstellung. ein, wenn die Schwerkraft größer ist als die Centrifugalkraft oder gleich groß (Schema $A$ ), einmal wenn die Centrifugalkraft größer ist (Schema $B$ ).

\section{Eier in den Hïllen fixirt und rotirt.}

Hier unterliegt der Eiinhalt an sich den einwirkenden Kräften. Als solche kommen in Betracht

1) die von außen angreifende Kraft, die Schwerkraft oder die Resultante aus ihr und der Centrifugalkraft,

2) die Kohäsion der Bestandtheile des Inhalts des Eies bezw. ihre Reibung an der Eihaut. Da die äußere Kraft in jedem Moment in anderer Richtung auf das System des Eiinhalts einwirkt, so wird sie eine Verschiebung des Schwerpunktes im Ei, d. h. eine Mischung der Massen und Zerstörung des ursprünglichen Gefüges zur Folge haben, wenn sie größer ist, als die Kohäsionskraft.

Aus den Versuchen von Bors (8) u. A. geht hervor, dass die Schwerkraft größer ist, als die Kohäsion des Inhalts des Froscheies. Die Resultante von Schwerkraft und Centrifugalkraft ist nun oft größer als die erstere allein. Um so mehr wird sie größer sein, als die Kohäsion. Daher das baldige Absterben fixirter rotirter Eier. wie es Schcltze beobachtete. Wird die Centrifugalkraft gleich oder wenig größer als die Schwerkraft, so ist die Resultante in der unteren Hälfte der Umdrehung größer, in einem großen Theil der oberen aber kleiner als die Schwerkraft. Sie kann desshalb dort auch kleiner werden als die Kohäsion, so dass der Eiinhalt durch sie keine nennenswerthe Umordnung ${ }^{1)}$ erfahren wird. Für eine solche käme nur die untere Hälfte des Weges in Betracht. Hier aber bilden die Resultanten der äußeren Kräfte in den entsprechenden Phasen der beiden Viertelkreisbogen gleiche und entgegengesetzte Winkel zum Loth bezw. zur Symmetrieachse des Eies ${ }^{2}$ ), d. h. sie sind bestrebt ihre Wirkungen gegenseitig aufzuheben. Daraus folgt mit Wahrscheinlichkeit, dass unter Umständen auch das fixirte Ei trotz der

1. Deren Größe wird wieder durch die Resultante aus der Kohäsionskraft als der einen und der Resultante von Schwer- und Centrifugalkraft als der anderen Komponente bestimmt.

2. Als Ausgangsstellung für die Rotation ist die tiefste Einstellung gedacht und das Ei fixirt angenommen in einer Lage, in der seine Achse mit dem Loth zusammenfiallt. 
Rotation einer seine Entwickelung erheblich störenden Umordnnig des Inhaltes entgehen kann.

Aus dem Gesagten ergiebt sich der Schluss, dass

1) ein Rotirenlassen von frei in ihren Hüllen beweglichen Eiern um eine feste Achse mit gleichmäßiger Geschwindigkeit keinen Aufschluss über die Entbehrlichkeit der richtenden Wirkung der Schwerkraft geben kann, weil dieselbe durch eine gleichartig wirkende Kraftersetzt wird;

2) ebensowenig ein Rotirenlassen fixirter Eier, weil es sich hier nicht um eine Ausschaltung der richtenden Kraft, sondern um das Einführen einer den Eiinhalt umordnenden Kraft, Schwerkraft oder Kombination derselben mit der Centrifugalkraft handelt ${ }^{1}$ ).

Es erhebt sich nun die Frage: Giebt es kein Mittel, jede äuBere richtende Krafteinwirkung vom Froschei fernzuhalten und zu sehen, ob es sich doch entwickelt?

Ich meine ja; vernichten können wir zwar die Schwerkraft nicht, wohl aber können wir sie praktisch unwirksam machen, worauf es ja hier allein ankommt. Wir brauchen nur den Versuch so anzuordnen, dass der Effekt, den eine änBere richtende Kraft im einen Moment setzen will, durch eine in anderer Richtung einwirkende Kraft im nächsten Moment wieder aufgehoben wird. Es wird dann zu keiner erheblichen Störung in der Struktur des Eies kommen, sofern die einwirkenden Kräfte so klein im Vergleich zur Kohäsion sind, dass die von ihnen in einem Moment angestrebten Verschiebungen der verschiedenen Substanzen des Eiinhalts gleich Null gesetzt werden können. Darum und trotz des Fehlens einer richtenden Kraft entwickeln sich dann die Eier normal, wie der Erfolg lehrt. Ob das Ei bei einem derartigen Versuch in seiner Hülle drehbar ist oder nicht, ist naturlich einerlei.

Diesbezligliche Versuche, zunächst in anderer Absicht als der, das vorliegende Problem zu studiren, stellte ich im Frühjahr 1900 an. Vorausschicken will ich, dass der angewandte Apparat sehr primitiv ist. Unter der Einfachheit der Technik eines Versuchs braucht aber nicht die Exaktheit und seine Beweiskraft zu leiden; unter dieser Voraussetzung wird die Einfachheit einen Vorzug bilden, weil

1) Hierher gehören auch die Versuche HerTwig's 11) an Eiern unter Anwendung einer die Kohäsion der Theilchen des Eiinhalts übertreffenden Centrifugalkraft. Nicht die veränderte Richtung, sondern die gesteigerte Intensität der :ußeren Kraft gab hier den Anlass zu abnormaler Entwickelung. 
dann der betreffende Versuch leichter der Kontrolle von anderer Seite zugänglich ist.

Im März 1900 setzte ich einen Laichballen ron Rana fusca, dessen Eier im Beginu der Urmundbildung standen, in ein $15 \mathrm{~cm}$ weites Cylinderglas. In dasselbe tauchte eine überall gleich weite Glasröhre bis nahe auf den Boden, die durch einen Gummischlauch mit einem durch die Wasserleitung zu betreibenden Durchliiftungsapparat in Verbindung stand. Dieser lieferte je nach Belieben einen stärkeren oder schwächeren Luftstrom, welcher im Wasser in rasch auf einander folgenden Blasen aufsteigend das Wasser und den Laichballeı in ständiger Bewegung hielt. Die Form der Bewegung lässt sich im großen Ganzen eine Rotationsbewegung nennen, unterscheidet sich aber von der des Klinostaten dadurch, dass sie um keine feste Achse herum stattfand, und ihre Geschwindigkeit sowohl bei Vergleichung. der einzelnen Touren ${ }^{1)}$ unter einander, als auch in den verschiedenen Strecken einer Tour stets wechselte. Nach physikalischem Sprachgebrauch war sie eine ungeordnete. Sobald der Eierballen in die Nähe der Mündung des Glasrobres kam, wurde er mit großer Geschwindigkeit nach oben gerissen, trieb an der Oberfläche zugleich sinkend nach der anderen Seite, kam auf den Grund, wurde iiber diesen hinweg wieder in den Bereich des aufsteigenden Luftstroms geführt und begann seinen Weg ron Neuem. Dazu kamen riittelnde und schüttelnde seitliche Bewegungen, namentlich dann, wean der vordere Theil des Eierballens schon vom Luftblasenstrom erfasst war. aber durch das nachschleppende hintere Stiick gehemmt, seine Geschwindigkeit noch nicht theilen konnte.

Von einer Orientirung der Eiachse in der Gravitationsrichtung oder irgend einer länger als einen Moment richtend wirkenden Kraft war dabei gar keine Rede. Davon konnte man sich zum Überfluss jeden Augenblick überzeugen. Unter andauernd gleichen Verhältnissen verlief die Entwickelung bis zur Ausbildung normaler, freischwimmender Larven.

Nachdem ich aus den Arbeiten PfLëger's dessen Ansichten über einen wahrscheinlichen Einfluss der Schwerkraft anf die Lage der beiden ersten Furchungsebenen und des Urmunds kennen gelernt hatte, operirte ich im Frühling 1901 mit frisch befruchteten Eiern. Die Verhältnisse waren ungünstig, indem die außergewöhnlich kalte Witterung im März die Grasfrösche bis Ende des Monats im Winterquartier

1: Ihre Anzahl wurde zwisehen 18 und 40 in der Minute gehalten. 
zurỉckhielt, und am ersten schönen Tage fast alle glcichzeitig dasselbe verließen und sofort ablaichten. Nur mit Mühe gelang es daher, am 6. April noch vier lajchfähige Paare aufzntreiben; der Laichtrieb war auch bei ihnen so stark, dass eines der Weibchen, obschon isolirt, in der Nacht zum 7. seine Eier absetzte, und ich auf nur drei Paare angewiesen war. Ich erwähne Vorstehendes desshalb, weil gegen Ende der Laichperiode die Eier bekanntlich weniger widerstandsfähig, insbesondere nach Roux's Angaben weniger regulationsfähig sind, die angestellten Versuche aber trotzdem vollständig gelangen.

Es genügt, wenn von den drei gleichartig verlaufenen Versuchen einer besprochen wird.

Am 8. April, $10 \mathrm{~V}$. wurden die Eier des einen Weibchens nach der Anweisung von Roux (Anat. Anz. Bd. 9) besamt. Dieselben klebten am Boden der Glasschale zu einem flachen Fladen zusammen, der halbirt und um $10^{30} \mathrm{~V}$. auf ein Glas mit ruhendem und eines mit in oben beschriebener Weise bewegtem Wasser vertheilt wurde. Gerade die flächenhafte Ausbreitung des Laiches ist ein Vortheil, weil so die Lagen der einzelnen Eier leichter kontrollirt werden können und die oben erwähnten rittelnden Bewegungen aus leicht ersichtlichem Grunde sich noch intensiver gestalten.

Bei beiden Partien war um $3^{15} \mathrm{~N}$. die erste, um $4^{30}$ auch die zweite Furche normal ausgebildet, wovon ich mich an herausgenommenen Proben überzengte. Vom Momente der Befruchtung 10 V. bis $8 \mathrm{~N}$. ließ ich den Versuch nur während einer halbstiundigen Mittagspause aus dem Auge, um ja nicht ein zeitweiliges Stocken der Wasserbewegung zu ubersehen. Dass auch in dieser und den folgenden Nächten der Apparat gut funktionirte, konnte ich ohne Miuhe kontrolliren, da ich das gurgelnde, von den aufsteigenden Luftblasen verursachte Geräusch deutlich in meinem iuber dem Arbeitsraum gelegenen Schlafzimmer hörte. Da die Lufttemperatur sich in der Folgezeit zwischen nur $11^{\circ}$ und $13^{\circ} \mathrm{C}$. bewegte, ging die Entwickelung langsam weiter. Am X. 11 V. begann die Gastrulation sichtbar zu werden. Am XI. $9^{30}$ V. hatten die Kontrollembryonen die Medullarplatte ausgebildet, der Dotterpfropf war klein. Die Embryonen in bewegtem Wasser zeigten schon jetzt deutlich ein Zuriickbleiben hinter denen im ruhigen Wasser, indem der Dotterpfropf bei ihnen noch viel größer war. Am XIII. $8 \mathrm{~V}$. begann bei der ruhenden Hälfte der Ruderschwanz sich abzuheben und am XIV. 7 V. waren die ersten Larven ausgefallen. Díe rotirenden Larven schliupften im Laufe des 15. April aus. In beiden Partien war eine größere Anzahl 
Eier bezw. Embryonen abgestorben, im bewegten Wasser aber weniger, was wohl auf die energische Zuführung von Sauerstoff durch die Durchliuftung zurickgefuhrt werden kann.

Dass die rotirenden Larven zwar normal, aber langsamer als die ruhenden ihre Entwickelung durchmachten, erklärt sich leicht aus dem Temperaturunterschied des Wassers in beiden Gläsern; obwohl dieselben neben einander standen, schwankte derselbe zwischen $0,5^{\circ}$ und $3^{\circ} \mathrm{C}$. Die geringere Temperatur des bewegten Wassers ist wiederum auf die stärkere Verdunstung desselben zurückzuftuhren in Folge der Bewegung und des Emporspritzens des Wassers am Glas. Ihre Größe wechselt mit dem Feuchtigkeitsgehalt und der Temperatur der Luft. Die beiden anderen Versuche ergaben ganz dasselbe Resultat; auch hier verlief die Entwickelung normal, obschon bei dem einen, der im kühlen Souterrain angestellt wurde, die Eier bezw. Embryonen noch viel länger der abnormalen Wasserbewegung ausgesetzt waren, nämlich über 11 Tage, vom IX. $10 \mathrm{~V}$. bis zum Ausfallen der Larven am XX. 8 N. ${ }^{1}$.

Die beschriebenen Versuche beweisen unzweideutig, dass weder die Schwerkraft noch eine andere von anßen richtend einwirkende Kraft für die normale Entwickelung des Froscheies die Bedeutung einer gestaltenden Ursache oder nothwendigen Bedingung hat.

Im Princip unterscheiden sich meine Versuche nicht von einem Experiment Roux's (4), bei dem Eier lose in einem Reagensglas mit Wasser untergebracht am Klinostaten rotirt wurden. Sie rutschten während der Drehung hin und her, uberschlugen sich, machten auch seitliche Bewegungen, entwickelten sich aber normal. Schultze (19; zweifelt nicht daran, dass die Eier durch einander kollerten und ihre Achse mit der Schwerkraft die verschiedensten Winkel bildete. Er erwähnte selbst fruher (10), dass Froscheier, die durch einen Wasserstrahl in beständiger Rotation erhalten werden, und Coregonus-Eier, welche sich in fortwährender Bewegung befinden, keine Entwickelungsstörung erleiden, weil dabei keine Substanzumordnungen im Ei stattfinden.

1) Versuche von YUNG :16, bei denen frischbefruchtete Eier starken stoßweisen Erschiitterungen, in Folge deren die Wasseroberfläche $\check{0}-6 \mathrm{~cm}$ hohe Wellen bildete, unterworfen wurden und zu Grunde gingen, stehen mit meinen Beobachtungen nicht im Widerspruch, da hier offenbar starke mechanische Insulte die Eier vernichteten. 
Über die bedingte Unabhängigkeit d. Entwickel. des polar differenz. Eies etc. 607

Dass in diesen Fällen, sowie in meinen Versuchen, die Entwickelung normal verläuft, ist zweifellos dem Umstand zu verdanken, dass dabei die Struktur des Eies ungestört bleibt. Welche Kraft ist es nun, die sie erhält? Nach SchuLrze die Schwerkraft, bezw. eine au $ß$ ere Kraft tiberhaupt.

Er meint nämlich mit Rïcksicht auf den letztgenannten Versuch von Roux, es sei dabei von Fall zu Fall zu unterscheiden, wie weit die Schwerewirkung durch Centrifugalwirkung ersetzt werde. Bestehe aber keine Centrifugalkraft, so gelte dasselbe wie für die in ihren Hüllen drehbaren anderen Klinostateneier, dass nämlich die Schwerkraft nicht aufgehoben sei und vortibergehend Normalstellung eintrete. In den momentan wirkenden abnormen Einstellungen aber gewinne die abnorm angreifende Schwerkraft keine Zeit, die normale Struktur zu beeinflussen.

Dieser Einwand ist größtentheils schon oben besprochen worden. Nur noch einige Worte darüber, ob bei meinen Versuchen ein Ersatz der richtenden Schwerkraft durch Centrifugalwirkung eingewendet werden kann oder nicht.

Wie schon erwähnt, besaßen die Eier während der einzelnen Strecken eines Umlaufs verschiedene Geschwindigkeiten, so dass von einer Vertretung der stets gleich großen Schwerkraft durch eine sich gleichbleibende Resultante wegen des steten Wechsels der Centrifugalkraftgröße keine Rede ist. In einer, bei den auf einander folgenden Touren wechselnden Reihenfolge durchliefen die Eier außerdem alle möglichen abnormalen Stellungen, denen gegenüber die vielleicht $\mathbf{a b}$ und zu eintretenden, auch nur momentaren normalen Lagen in ihrer "die Struktur des Eies sichernden Wirkung gar nicht in Betracht kommen.

Was dem Ei seine angeborne Struktur erhält, ist die K ohäsion der Theilchen seines Inhalts, wie Roux (20) mit Recht gegen ScHulize geltend macht.

Wenn beim normal gelagerten Ei die verschiedenen Bestandtheile den Forderungen der Schwerkraft entsprechend geordnet sind, so verdankt es weder die Entstehung noch die Erhaltung dieser Ordnung der Schwerkraft. Noch weniger darf letztere, wie dies von Schultze (19) geschieht, als Retterin des >hilflos daliegenden Eies « hingestellt werden. Vielmehr ist sie bei einer abnormen Lage der angreifende Theil und das Ei rettet sich durch seine Drehfähigkeit.

Wenn in einem unbeaufsichtigten Dampfkessel die Dampfspannung eine gefahrdrohende Höhe erreicht, und der Kessel durch Öffnen 
des Sicherheitsventils dem Zerplatzen entgeht, wer hat den Dampfkessel dann gerettet? Der hohe Dampfdruck, weil er das Ventil offnete, oder das Vorhandensein des Ventils, das ohne ihn gar nicht nöthig gewesen wäre?

Es mag noch kurz auf die Frage eingegangen werden, ob die Äußerungen der Sehwerkraft, wie sie bei den Froscheiern im Bestreben, sich in die Erdachse einzustellen bezw. in den Rotationen des Embryo sich kundgeben, mit dem Ge otropismus der Pflanzen verglichen werden können. Schwendener (Ges. Botan. Mittheilungen Bd. I. 1898. pag. 412) unterscheidet bei Pflanzen zwischen geotropischen Krümmungen und Wirkung des Eigengewichts. Beides ist scharf von einander zu trennen. Schwendener zeigte durch Versuche, dass an einer windenden Pflanze, wenn das Eigengewicht der Spitze durch ein Gewicht vollständig kontrebalancirt ist, die Pflanze doch zu winden fortfährt, bezw. die geotropische Wirkung nicht beeinträchtigt wird.

Was nun an Froscheiern zu beobachten ist, stellt offenbar nur eine Folge der excentrischen Lage des Schwerpunktes dar; das Froschei sucht, aus seiner Ruhelage gebracht, immer wieder in dieselbe zurïckzukehren, gerade wie eine leblose, aus verschieden schwerem Material zusammengesetzte Kugel unter gegebenen Verhältnissen dasselbe thut. Ebenso sind die Rotationen des Embryo rein mechanische Folgeerscheinungen der durch Wachsthumsvorgänge bewirkten Verschiebung des Schwerpunkts. Für einen Vergleich mit geotropischen Reizwirkungen bieten diese Erscheinungen am thierischen Organismus keinerlei Handhabe.

In kurzer Zusammenfassung ergiebt sich entgegen den Auffassungen Pflëger's und O. Schultze's der Schlusssatz: Der Schwerkraft kommt für die normale Entwickelung des Froscheies weder die Bedeutung einer gestaltenden Kraft (PFL ̈́GER), noch die einer nothwendigen Bedingung (Schultze) zu.

Dass das $\mathrm{Ei}$ sich ihr als einer gegebenen äuBeren Bedingung anpassen muss und anpasst (Ausbildung der Drehfähigkeit), bezw. wenn die Anpassung gestört wird, von der Schwerkraft zu Grunde gerichtet werden kann (in umgekehrter Lage fixirte Eier), steht damit in keinem Widerspruch. 
Über die bedingte Unabhïngigkeit d. Entwickel. des polar differenz. Eies ete. 609

\section{Litteraturverzeichnis.}

1) Pflüger, E., Über den Einfluss der Schwerkraft auf die Theilung der Zellen. Pflüger's Archir. Bd. 31. 1883.

2 _- Über den Einfluss der Schwerkraft anf die Theilung der Zellen und auf die Entwicklung des Embryo. Ebenda. Bd. 32. 1883.

3) - - Über die Einwirkung der Schwerkraft und anderer Bedingungen auf die Richtung der Zelltheilung. Ebenda. Bd. 34. 1884.

4) Roux, W., Über die Entwickelung der Froscheier bei Aufhebung der richtenden Wirkung der Schwere. Breslauer ärztl. Zeitschr. 1884.

5 ) RAUber, A., Schwerkraftversuche an Forelleneiern. Berichte d. naturforsch. Ges. Leipzig. 1884.

6 — Über den Einfluss der Schwerkraft auf die Zelltheilung und das Wachsthum. Ebenda. 1884.

7) Hertwig, 0., Welchen Einfluss uibt die Schwerkraft auf die Theilung der Zellen? Jen. Zeitschr. f. Naturwiss. Bd. 18. 1884.

8. Bons, G., Über den Einfluss der Schwere auf das Froschei. Archiv f. miki. Anat. Bd. 24. 1885.

9) Schultze, O., Über die unbedingte Abhängigkeit normaler tierischer Gestaltung von der Wirkung der Schwerkraft. Verhandl. Anat. Ges. 1894.

10 - Über die Bedeutung der Schwerkraft für die organische Gestaltung. Verhandl. Phys.-med. Ges. Würzburg. Bd.28. 1894.

11) Hertwig, 0., Über einige am befruchteten Froschei durch Centrifugalkraft hervorgerufene Mechanomorphosen. Sitzungsber. Preuß. Akad. d. Wiss. Berlin. 1897.

12) Schultze, O., Neue Untersuchungen über die Bedeutung der Schwerkraft für die Entwickelung. Verhandl. Phys.-med. Ges. Würzburg. 1897.

13. - Nene Untersuchungen zur Frage von der Notwendigkeit der Schwerkraft für die Entwickelung. Verhandl. Anat. Ges. 1897.

14. Roux, W., Bemerkungen zu O. SCHLLtzE's meven Rotationsversuchen an Froscheiern. Archiv f. Entwickelungsmech. Bd. V. 1897.

15) Hertwig, O., Die Zelle und die Gewebe. 2. Buch. 1898.

16) YUNG, E., Influence de mouvements de vague sur le développement des larres de grenouille. Compt. rend. 'T. 126. Paris 1898.

17. Schurtze, 0., Über die Nothwendigkeit der freien Entwicklung des Embryo. Archiv f. mikr. Anat. Bd. 55. 1899.

18, Roux, W., Bemerkungen zu 0. Schultze's Arbeit iiber die Nothwendigkeit der sfreien Entwickelung « des Embryo sowie der snormalen Gravitationswirkung a zur Entwickelung. Archiv f. Entwickelungsmech. Bd. IX. 1900.

19. Schultze, 0., Zur Frage von der Bedeutung der Schwerkraft für die Entwicklung des thierischen Embryo. Archiv f. mikr. Anat. Bd. 56. 1900.

20, Rovx, W., Berichtigungen zu 0 . Schultze's jiingstem Aufsatz iiber die Bedeutung der Schwerkraft fuir die Entwickelung des thierischen Embryo und Anderes. Archiv f. Entwickelungsmech. Bd. X. 1900. 